\title{
EVENTOS FENOLÓGICOS DE COPAÍBA (Copaifera officinalis L. - CAESALPINIACEAE) EM MATA DE GALERIA DO RIO BRANCO, BOA VISTA/RORAIMA, BRASIL: UMA PRIMEIRAAPROXIMAÇÃO*
}

\author{
Martinho Alves de ANDRADE JÚNIOR', Isolde Dorothea Kossmann FERRAZ²
}

\begin{abstract}
RESUMO - Árvores de copaiba pertencem ao gênero botânico Copaifera, da família Caesalpiniaceae, e são conhecidas em toda a Amazônia principalmente pela importância medicinal atribuida ao seu óleo-resina e sua casca. Este trabalho refere-se à observação dos eventos fenológicos de 60 árvores de Copaifera officinalis, presentes em área de mata de galeria do rio Branco, em Boa Vista/RR, durante o periodo de janeiro/1996 a janeiro/1998. Os dados climáticos locais indicam estacionalidade bem definida, com um período seco geralmente estendendo-se desde setembro/ outubro a março/abril e um periodo chuvoso concentrado principalmente entre os meses de maio e agosto. A sucessão dos principais eventos fenológicos das árvores de $C$. officinalis ocorreu entre os meses de setembro a março, com o início da floração coincidindo com o início do período seco (setembro), o período de frutificação estendeu-se de novembro até março com o pico de dispersão das sementes ocorrendo no final de fevereiro até início de março. Os padrões fenológicos de $C$. officinalis são comparados com algumas espécies do mesmo gênero botânico $(C$, multijuga, $C$. langsdorfii e $C$. pubiflora) situadas em outras regiōes da América do Sul.
\end{abstract}

Palavras-chave: fenologia, floração, frutificação, dispersão das sementes, caducifolia

Phenologic Events of Copaiba Trees (Copaifera officinalis L. - Caesalpinaceae) in the Gallery Forest of the Branco River, Boa Vista/Roraima State, Brazil: A First View

ABSTRACT - Copaiba trees belong to the genus Copaifera (Caesalpiniaceae) and are wellknown in the Amazon region for the medical use of its resin-oil and bark. This study reports the phenologic events observed between January 1996 and January 1998 on 60 Copaifera officinalis trees localized in a gallery forest along the Branco River near Boa Vista. The local climatic data for this region indicate a strong seasonality. Dry season occurs between September/October to March/April and rainy season occurs mainly between the months of May and August. The principal phenologic events of the $C$. officinalis trees occurred between September and March. Flowers first appeared at the beginning of dry season (September). Fruits were observed between November and March and seed fall showed a peak of seed-shedding in the second half of February and beginning of March. The phenologic events of $C$. officinalis trees are discussed and compared with information on other species of the same genus (C. multijuga, C. langsdorfii e $C$. pubiflora) occurring in other regions of South America.

Key-words: phenology, flowering, fruiting, seed dispersal, deciduous

\section{INTRODUÇÃO}

\section{O gênero Copaifera}

(Caesalpiniaceae) apresenta uma distribuição geográfica basicamente tropical, com cerca de 25 espécies na América do Sul (Dwyer, 1951; 1954).
As plantas deste gênero são conhecidas no Brasil pelo nome vulgar de copaiba, copaibeira, pau-d'óleo, sendo utilizadas principalmente devido às propriedades medicinais do óleo-resina e da casca, extraídos do tronco.

\footnotetext{
* Este trabalho é parte da Dissertação de Mestrado do primeiro autor - Curso Botânica/INPA, abril/1998

'Museu Integrado de Roraima, Setor de Botânica; Av. Brigadeiro Eduardo Gomes, s/n - Parque Anauá - CEP: 69.305-010-Boa Vista/RR

${ }^{2}$ INPA/CPST - Caixa Postal 478, CEP: 69.011-970 - Manaus/AM
}

ACTAAMAZONICA 30(4): 523-533, 2000. 
Das espécies de Copaifera encontradas no Brasil, $C$. langsdorfii apresenta a mais ampla distribuição geográfica, ocorrendo desde o Maranhão até o Paraná (Barbosa, 1990; Carvalho, 1994). Copaifera officinalis distribui-se principalmente na região Norte do Brasil, nos estados do Pará, Rondônia e Roraima, com registros nos Herbários do Instituto Nacional de Pesquisas da Amazônia, Museu Paraense Emílio Goeldi, Centro de Pesquisa Agroflorestal da Amazônia Ocidental (Embrapa-Pará) e Museu Integrado de Roraima. Em Roraima, habita diferentes ecossistemas, desde áreas de mata de galeria até áreas de savana (Ducke, 1949).

Em relação a estudos fenológicos, poucos trabalhos se referem às árvores de copaiba, sem haver informações sobre $C$. officinalis. Até o presente, apenas $C$. multijuga foi pesquisada quanto à fenologia, em floresta de terra firme na Amazônia Central (Alencar et al., 1979; Alencar, 1988). Algumas informações referentes a outras espécies do mesmo gênero podem ser obtidas de publicações, que não tratam especificamente da fenologia (Ramírez \& Arroyo, 1982; Janzen, 1983; Crestana \& Kageyama, 1989; Barbosa, 1990; Lorenzi, 1992). Portanto, o presente estudo teve como objetivo investigar, em uma primeira aproximação, os eventos fenológicos de árvores de $C$. officinalis presentes em área de mata de galeria do rio Branco, na região de Boa Vista/Roraima.

\section{MATERIAL E MÉTODOS}

As árvores-matrizes de Copaifera officinalis selecionadas para este estudo encontraram-se em áreas de mata de galeria na margem direita do rio Branco, aproximadamente $12 \mathrm{~km}$ ao Sul da cidade de Boa Vista - Roraima, próximo ao Distrito Industrial, com as coordenadas $2^{\circ} 46^{\prime} \mathrm{N}$ e $60^{\circ} 41^{\prime} \mathrm{W}$ (Fig. 1).

O clima de Boa Vista é do tipo Aw, da classificação de Köppen. Caracterizando-se como clima tropical úmido, com precipitação média do mês mais seco inferior a $60 \mathrm{~mm}$ _(SUDAM, 1984). A precipitação média anual é de $1.614 \mathrm{~mm}$, com $58 \%$ das chuvas ocorrendo entre maio e julho, e $9 \%$ entre dezembro e março (Barbosa, 1997), período este considerado seco, segundo curva ombrotérmica de Gaussen (Radambrasil, 1975).

O solo é do tipo Latossolo amarelo, textura argilosa, com baixa fertilidade natural e toxidez por Alumínio (EmbrapaRoraima/Laboratório de Análise de Solos e Plantas).

Dados de precipitação, temperatura e umidade relativa do ar foram obtidos da Estação Boa Vista (Força Aérea Brasileira/ Destacamento de Proteção ao Vôo), referentes aos anos 1995, 1996 e 1997, para fins de comparação com as observações fenológicas.

Foram inventariadas 60 (sessenta) árvores de copaiba em aproximadamente 15 hectares, para registro dos eventos fenológicos, identificando-se as épocas de mudança foliar, floração, frutificação e dispersão das sementes, utilizando-se binóculo (7-15 x 30), e através da coleta de material botânico. Observouse ainda, além das árvores inventariadas, outras árvores 


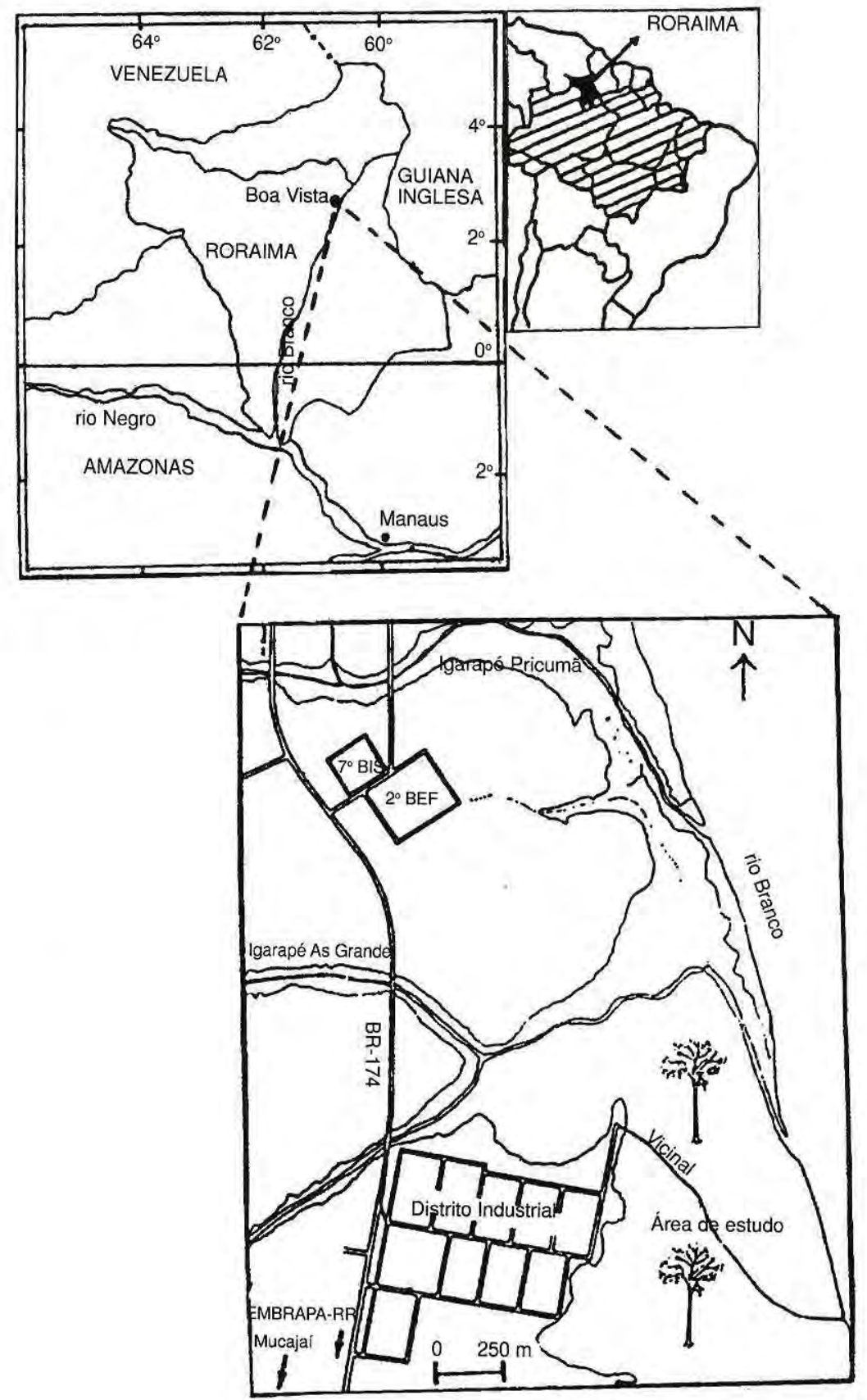

Figura 1. Mapa ilustrativo do local de estudo; coordenadas: $2^{\circ} 46^{\prime} \mathrm{N}$ e $60^{\circ} 41^{\prime} \mathrm{W}$. 
ocorrendo nas proximidades da área de estudo para verificar se exibiam o correspondente estádio fenológico. O período de observação compreendeu cerca de 20 meses, entre fevereiro de 1996 e janeiro de 1998, e se estendeu para observações complementares nos meses de julho de 1998 a maio de 1999. Foram quantificadas mensalmente as árvores em cada fenofase e determinado um estágio fenológico, quando o mesmo estava sendo manifestado na maioria das árvores.

\section{RESULTADOS}

Os dados meteorológicos da Estação Boa Vista (FAB/DPV) revelam diferença acentuada na precipitação entre os anos de 1995 , 1996 e 1997 (Fig. 2). O ano de 1996 foi marcado por fortes chuvas. O transbordamento do leito do rio Branco atingiu parte da zona urbana de Boa Vista. Nos meses de julho e agosto, o acesso à área de estudo na mata de galeria só foi possível de barco. O nivel da água atingiu cerca de $2 \mathrm{~m}$ de altura nos troncos das árvores selecionadas.

Em 1997, registrou-se uma precipitação acima de $100 \mathrm{~mm}$ nos meses de janeiro e fevereiro. Em março, houve uma precipitação quase nula, com a subseqüente estação chuvosa marcada por poucas chuvas. O total de chuvas registradas em 1997 até novembro não excedeu $1.200 \mathrm{~mm}$, contra cerca de $1.500 \mathrm{~mm}$ em 1995 , e $1.800 \mathrm{~mm}$ no ano de 1996 , para o mesmo período.

A iniciação floral nas árvores de
Copaifera officinalis teve início em setembro, com picos de anteses ocorrendo aproximadamente 60 dias mais tarde, sendo, entre final de outubro e início de novembro (Fig. 3). As inflorescências com os botões florais são difíceis de observar. No entanto, no pico da antese, as copas das árvores exibem apreciável efeito paisagístico, pela abundância de panículas florais esbranquiçadas.

Observou-se na copa das árvores, por ocasião da escalada para coletas botânicas, entre 01 e 28 de outubro de 1997, que o desenvolvimento da inflorescência não foi uniforme. As flores da base desenvolveram-se antes que as do ápice da inflorescência, o que dificulta a clara definição entre o início e o final da fenofase reprodutiva. Havia estádios distintos, ocorrendo ao mesmo tempo, nos diversos ramos de uma mesma árvore-matriz, como ramos apenas com botões florais, outros com flores em antese e outros com flores já fecundadas sem as sépalas do cálice, com estigma persistente e com pequenos ovários escuros em desenvolvimento.

Das 60 árvores inventariadas, observou-se que $58,3 \% \quad(n=35)$ exibiram floração e frutificação nos dois anos (1996 e 1997), 25\% ( $n=15)$ floresceram e frutificaram em apenas um ano e $16,7 \%(n=10)$ não exibiram floração.

O período de frutificação apresenta-se como o mais extenso, prolongando-se por cerca de 4,5 meses, desde novembro até março. Grande quantidade de frutos imaturos 


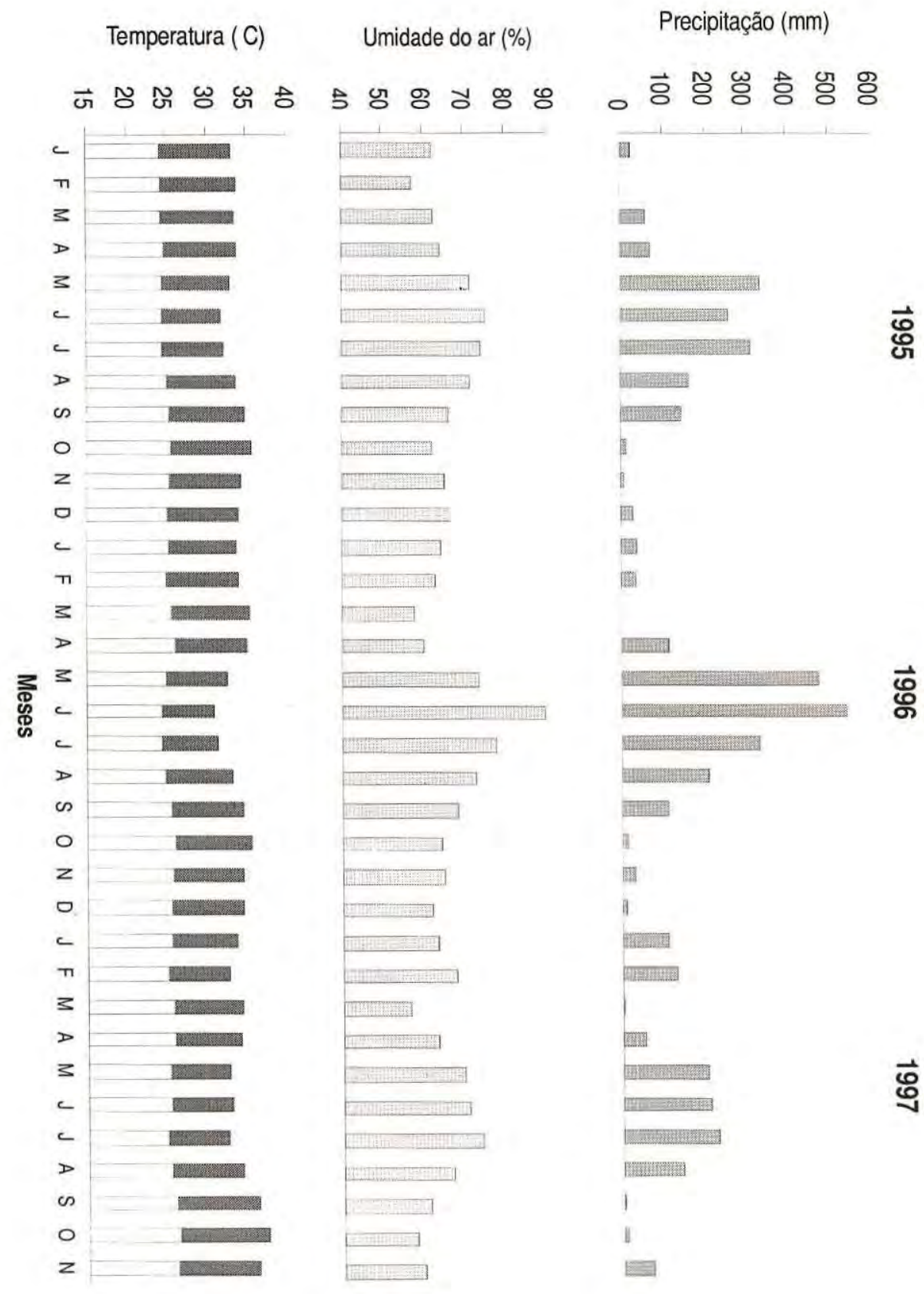

Figura 2. Dados de pluviosidade, umidade relativa do ar e temperatura máxima e minima da Estação Boa Vista (FAB/DPV), referentes às médias mensais dos anos 1995, 1996 e 1997. 
abortados foram verificados principalmente no mês de dezembro. As sementes, neste período, apresentaram-se pouco desenvolvidas, com rudimentos de arilo.

A fase de queda de sementes de $C$. officinalis teve início a partir da segunda quinzena de janeiro. Neste periodo, as copas das árvores exibiram frutos em diferentes estádios de maturação, com frutos verdes, vermelhos e marrons. Os frutos marrons iniciaram a deiscência, expondo as sementes envoltas pelo arilo. Sob a copa, observou-se principalmente sementes amarronzadas e poucas com cor preta e com arilo branco carnoso. $\mathrm{O}$ pico da dispersão das sementes ocorreu em fevereiro e as copas das árvores exibiram principalmente frutos de coloração marrom. As sementes apresentavam coloração totalmente preta, envoltas pelo arilo carnoso branco, embora algumas com arilo pouco ressecado. No final de março, constatou-se o término da dispersão das sementes, com grande quantidade de folhas caindo.

A fase de mudança foliar em $C$. officinalis ocorreu entre final de março e início de abril, após a frutificação e a dispersão das sementes. Entre a fase de perda total de folhas e a renovação da copa com folhas novas, registrouse um periodo em torno de 20 dias.

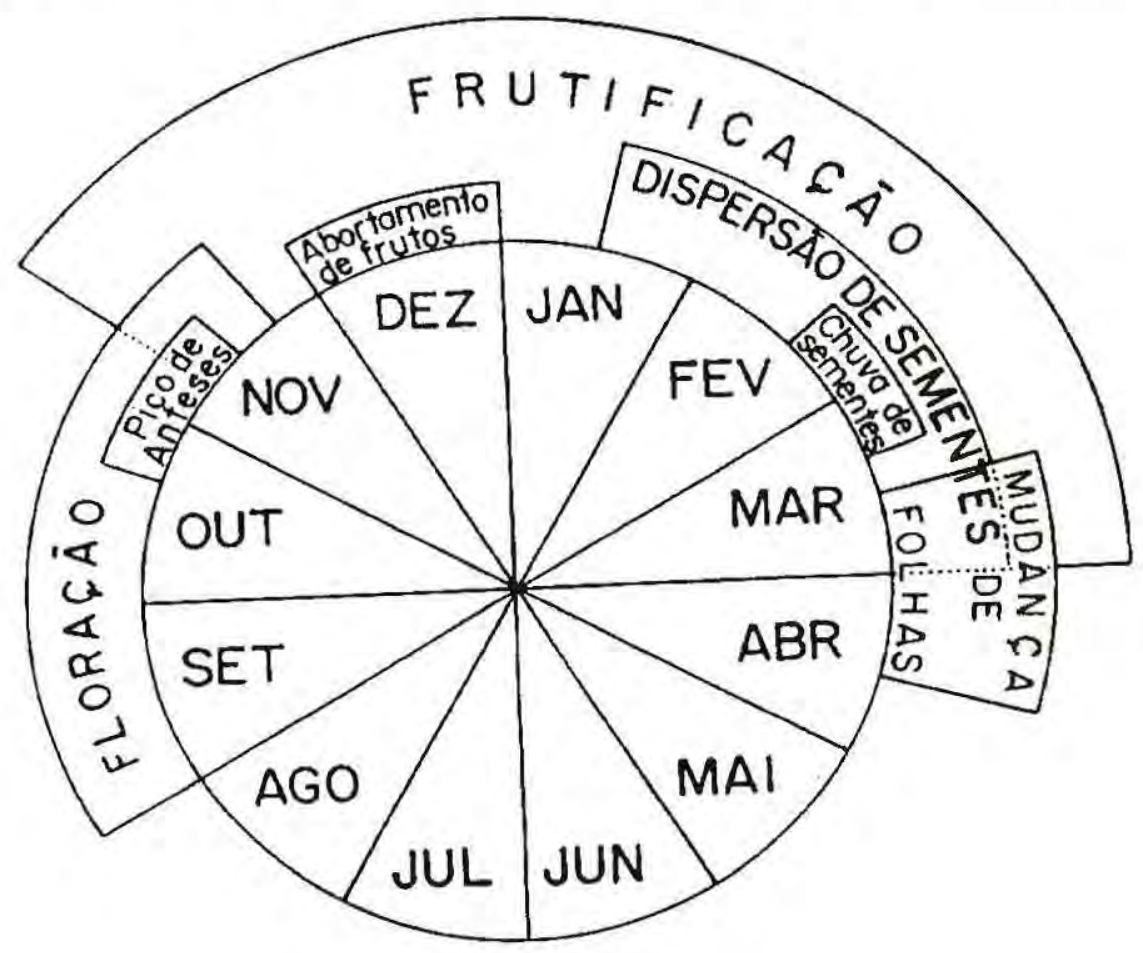

Figura 3. Esquema dos eventos fenológicos de Copaifera officinalis L., baseado nas observaçōes realizadas entre jan/1996 e jan/1998, em mata de galeria do rio Branco, Boa Vista - RR. 
Porém, nem todas as árvores apresentaram perda total de folhas, caracterizando um comportamento semicaducifólio antecedendo a estação chuvosa.

A Tabela 1 apresenta os registros de campo com descrições detalhadas dos eventos fenológicos de C. officinalis de acordo com os meses de observações.

\section{DISCUSSÃO}

O padrão de chuvas exibido em 1995 está em conformidade com a pluviometria normal da região (Barbosa, 1997). Porém, as fortes chuvas em janeiro e fevereiro de 1997, com valores acima de $100 \mathrm{~mm}$, foram excepcionais, pois janeiro e fevereiro são normalmente caracterizados por chuvas esporádicas e de reduzida intensidade.

$\mathrm{O}$ presente estudo não permite ainda determinar a regularidade de floração de Copaifera officinalis, apenas caracteriza um padrão irregular. C. multijuga apresenta floração e frutificação em intervalos de 2 anos (Alencar, 1988) e C. pubiflora produz sementes a intervalos regulares de 2,5 anos, com picos de produção a cada 5 anos (Janzen, 1983). C. langsdorfii apresenta também irregularidade na frutificação (Crestana \& Kageyama, 1989).

Em 1996, poucas árvores de $C$. officinalis em floração foram registradas na área de mata de galeria do rio Cotingo por Silva (1998), em estudo com recursos tróficos de abelhas na região da maloca do Contão (Nordeste do estado de Roraima). Estes resultados contrastam com os obtidos na mata de galeria do rio Branco, pois em 1996 cerca de $82 \%(n=49)$ das árvores de C. officinalis exibiram floração, em comparação com 62\% $(n=37)$ em 1997.

Comparando-se a Figura 3 com os dados climáticos da Figura 2, verifica-se que o início da floração de C. officinalis ocorre em setembro, após a diminuição da precipitação e umidade relativa do ar, e um relativo aumento da temperatura. Fato constatado também em observações no mês de setembro de 1998, além dos anos 1996 e 1997. Em reforço, a coleta de material fértil de $C$. officinalis realizada por Ducke, em setembro de 1943 (Herbário MPEG, registro 17.917), às margens do rio Branco, nas imediações de Boa Vista/RR, apresenta caracteristica fenológica similar ao observado nas coletas procedidas em nosso estudo (Fig. 4).

Várias espécies tropicais são estimuladas para iniciarem a floração e frutificação pela redução na precipitação e umidade relativa do ar (Aubréville, 1938; Ducke \& Black, 1953; Holttum, 1953; Njoku, 1963; Araujo, 1970; Frankie et al., 1974 citados por Alencar et al., 1979). Fato observado também na região de Manaus/AM, porém C. multijuga não se enquadra neste padrão (Alencar et al., 1979).

Comparando-se a característica semicaducifólia de $C$. officinalis com os de outras espécies deste gênero, verifica-se que $C$. multijuga apresenta padrão perenifólio (Alencar, 1988), exibindo porém, algumas vezes, semicaducifolia após a frutificação 
Tabela 1. Descrição dos eventos fenológicos de Copaifera officinalis $\mathrm{L}$. baseada nas observações realizadas entre jan/1996 e jan/1998, em área de mata de galeria do rio Branco, Boa Vista RR.

\begin{tabular}{|c|c|}
\hline Meses & Descriçăo \\
\hline SET & $\begin{array}{l}\text { - Rudimentos de inflorescências; } \\
\text { - Botōes florais pouco desenvolvidos, reunidos em paniculas terminais. }\end{array}$ \\
\hline OUT & $\begin{array}{l}\text { - Inflorescências exibindo botōes florais bem desenvolvidos e outros em desenvolvimento, em uma mesma } \\
\text { raque, caracterizando o tipo de desenvolvimento acrópeto (assincrônico); } \\
\text { - Inflorescências vistosas, exibindo flores brancas em antese; }\end{array}$ \\
\hline NOV & $\begin{array}{l}\text { - Poucas inflorescências exibindo botōes florais; } \\
\text { - Flores em antese; } \\
\text { - Fim da floração; } \\
\text { - Queda de alguns frutos imaturos (verdoengos). }\end{array}$ \\
\hline DEZ & $\begin{array}{l}\text { - Grande quantidade de frutos abortados (verdoengos e amarronzados); } \\
\text { - Rudimentos de sementes e arilos em frutos abortados (amarronzados). }\end{array}$ \\
\hline JAN & $\begin{array}{l}\text { - Queda de frutos imaturos avermelhados e amarronzados; } \\
\text { - Queda de poucos frutos lenhosos desenvolvidos; } \\
\text { - Sementes em geral amarronzadas e algumas poucas pretas, envoltas em arilo branco, carnoso e } \\
\text { adocicado. }\end{array}$ \\
\hline FEV & $\begin{array}{l}\text { - Plena dispersão de sementes; } \\
\text { - Queda de frutos lenhosos desenvolvidos em grande quantidade, a grande maioria abertos; } \\
\text { - Grande quantidade de sementes envoltas em arilo carnoso (cobrindo entre } 2 / 3 \text { e } \$ / 4 \text { ), algumas poucas } \\
\text { com arilo ressecado e mesmo sem arilo, porém em menor quantidade; } \\
\text { - Copa apresentando grande quantidade de frutos fechados e abertos; } \\
\text { - Presença de pássaros: japiins (Cacicus cela, lcteridae) e tucano (Ramphastus sp., Ramphastidae). Várias } \\
\text { vezes vistos alimentando-se nas copas das árvores. Os japiins fizeram ninho na copa de algumas árvores } \\
\text { de copaiba; } \\
\text { - Inicio de queda de folhas. }\end{array}$ \\
\hline MAR & $\begin{array}{l}\text { - Queda de frutos abertos e quase sempre retorcidos sem sementes; } \\
\text { - Queda de sementes em menor quantidade, quase sempre com arilo ressecado: } \\
\text { - Fim de queda de sementes (todas as árvores); } \\
\text { - Grande quantidade de folhas caindo; } \\
\text { - Árvores com copa desnuda total (algumas) ou parcialmente: } \\
\text { - Brotaçōes foliares. }\end{array}$ \\
\hline ABR & - Árvores com copas refeitas com folhas novas verdes. \\
\hline $\begin{array}{l}\text { MAl a } \\
\text { AGO }\end{array}$ & - Árvores com copas apresentando folhas desenvolvidas. \\
\hline
\end{tabular}

(Alencar et al., 1979). Em $C$. exibida pelas árvores de $C$. officinalis langsdorfii, a queda de folhas acontece é a ocorrência dos eventos fenológicos com frutos ainda na copa das árvores, dentro do período considerado seco, na região de São Paulo (Lorenzi, assemelhando-se a C. pubiflora, na 1992). As folhas novas de $C$. Venezuela (Ramirez \& Arroyo, 1982) langsdorfii apresentam coloração e contrastando com o padrão exibido rosada, o que pode facilitar a distinção por $C$. multijuga, na região de taxonômica entre as espécies Manaus/AM (Alencar, 1988) e $C$. (Carvalho, 1994).

Uma característica marcante 1990). 


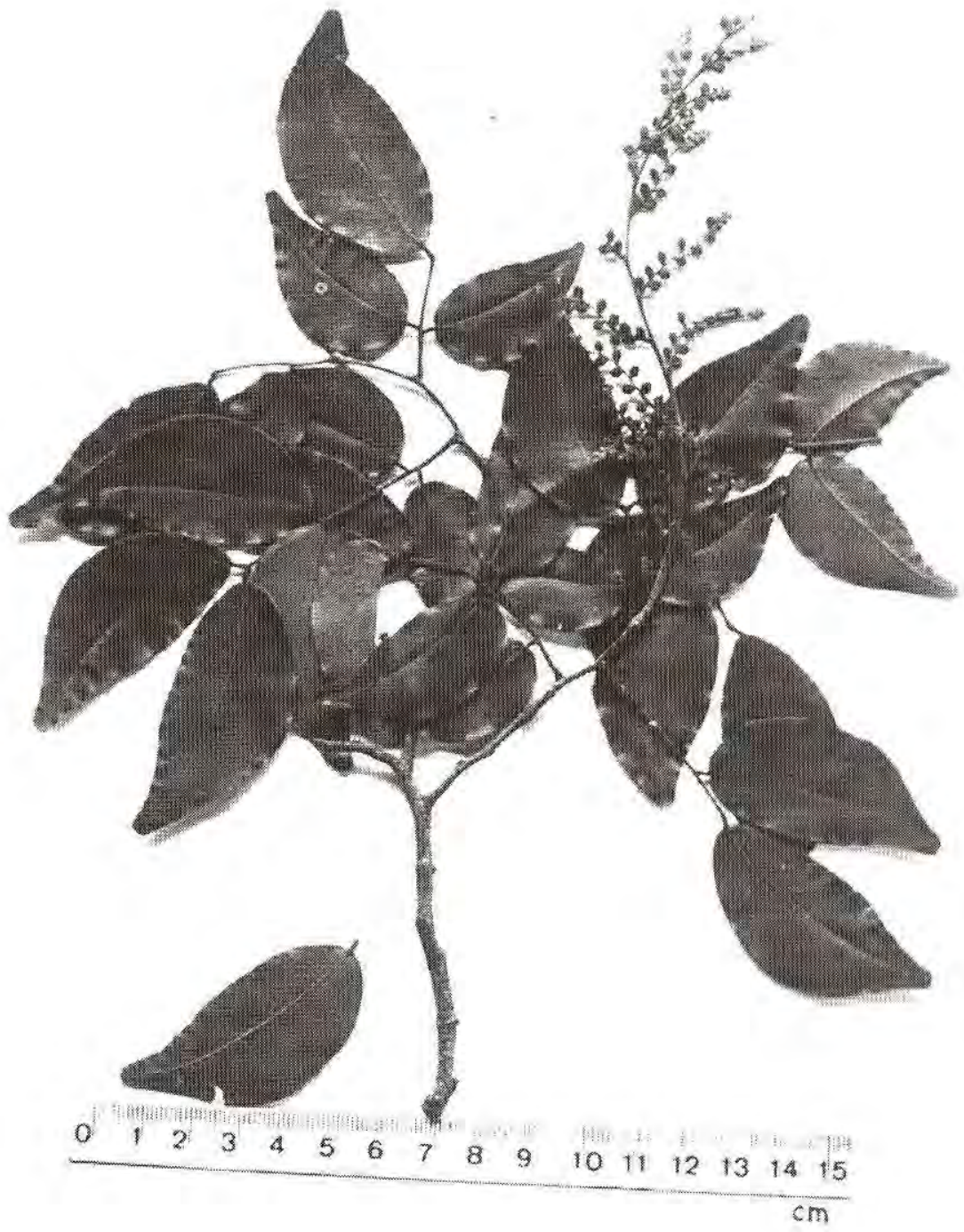

Figura 4. Ramo florífero de Copaifera officinalis L., fase de pré-antese, coletado em 10 de setembro de 1996, em mata de geleria do rio Branco, Boa Vista-RR. 
C. multijuga apresenta toda a floração na estação chuvosa (janeiroabril). A frutificação ocorre num periodo de aproximadamente 6 meses, com início no período de maior precipitação e o término no início do periodo seco (julho). Porém, o período considerado seco em Manaus/AM geralmente apresenta meses com precipitação maior que $100 \mathrm{~mm}$ (Alencar, 1988) e é bem mais curto (em torno de 4 meses) que aquele registrado na região de Boa Vista/RR (Barbosa, 1997). C. langsdorfii, em São Paulo/SP (Barbosa, 1990), também apresenta padrão bem distinto de $C$. officinalis. A iniciação floral e o pico de botões florais ocorre na época de maior precipitação (janeirofevereiro). Em abril, inicio do período considerado seco, as árvores apresentam-se com frutos. A fase de frutificação se estende até outubro/ novembro. O periodo de queda de sementes desta espécie coincide com o início da estação chuvosa (outubro).

Provavelmente, a distinção de padrões fenológicos entre $C$. officinalis, $C$. multijuga e $C$. langsdorfii, associa-se com a posição geográfica em relação à linha do Equador. Os regimes climáticos são bem distintos entre o hemisfério Norte e o Sul, e, portanto, podem influenciar nos aspectos fenológicos das espécies. A distribuição das chuvas em Manaus/ AM é bastante distinta daquela verificada em Boa Vista/RR, com periodo seco mais curto, normalmente entre julho e outubro. Em Boa Vista, o regime de chuvas inicia-se em abril e alcança maiores indices entre maio e agosto (65 a $78 \%$ das chuvas anuais), quase o inverso do padrão de chuvas de Manaus e completamente inverso em relação a São Paulo/SP.

Durante o período de dispersão de sementes de $C$. officinalis, registraramse pássaros, principalmente japiins (Cacicus cela), removendo sementes, na copa das árvores. De acordo com Ramírez \& Arroyo (1982), os japiins são eficientes agentes dispersores de sementes de $C$. pubiflora, na Venezuela.

\section{CONCLUSÕES}

A floração, frutificação e dispersão de sementes das árvores de Copaifera officinalis se sucedem ao longo da estação seca na região de Boa Vista/RR. A floração tem início em setembro, a frutificação se estende de novembro até março e o pico de dispersão das sementes ocorre em fevereiro. Antes do início da estação chuvosa (abril-maio), ocorre troca total ou parcial de folhas, caracterizando semicaducifolia.

C. officinalis apresenta padrão fenológico semelhante à espécie $C$. pubiflora, na Venezuela, e contrastante em relação às espécies $C$. multijuga (Amazônia Central) e C. langsdorfii (Região Sudeste), no Brasil.

\section{Bibliografia citada}

Alencar, J. da C. 1988. Estudos silviculturais de uma população natural de Copaifera multijuga Hayne - Leguminosae, na Amazônia Central. IV- Interpretação de dados fenológicos em relação a elementos climáticos. Acta Amazonica, 18(3/4):199209.

Alencar, J. da C.; Almeida, R. A.; Fernandes, 
N. P. 1979. Fenologia de espécies florestais em floresta tropical úmida de terra firme na Amazônia Central. Acta Amazonica, 9(1):163-198.

Barbosa, J. M. 1990. Maturação de sementes de Copaifera langsdorfii Desf. Tese de Doutorado, UNESP/FCAV, Jaboticabal, São Paulo. 144p.

Barbosa, R. I. 1997. Distribuição das chuvas em Roraima. In: Barbosa, R. I.; Ferreira, E.; Castellón, E. (eds). Homem, Ambiente e Ecologia em Roraima. Instituto Nacional de Pesquisas da Amazónia (INPA). Manaus, Amazonas. p.325-335.

Carvalho, P. E. R. 1994. Espécies florestais brasileiras: recomendações silviculturais, potencialidades e uso de madeira. Embrapa/CNPF. Brasília: Embrapa-SPI. p. 187-192.

Crestana, C. de S. M.; Kageyama, P. Y. 1989. Biologia de polinização de Copaifera langsdorfii Desf. (LeguminosaeCaesalpinioideae), o "óleo-de-copaiba". Rev. Inst. Flor, São Paulo: 1(1): 201-214.

Ducke, A. 1949. As leguminosas da Amazônia brasileira. In: Notas sobre a Flora Neotrópica - II. Boletim Técnico do Instituto Agronómico do Norte, Belém, Pará. 18: ( $2^{\mathrm{a}}$. ed. rev. e amp.) 248p.

Dwyer, J. D. 1951. The central american, west indian, and south american species of Copaifera (Caesalpiniaceae), Brittonia, 7(3): 143-172.

Dwyer, J. D. 1954. Further studies on the new world species of Copaifera. Bulletin of the Torrey Botanical Club, 81(3):179-187.

Janzen, D. H. 1983. Dispersal of seeds by vertebrate guts. In: Futuyma, D. J. \& Slatkin, M. (eds). Coevolution. Sinauer Associates. Sunderland, Massachusetts. p.222-262.

Lorenzi, H. 1992. Arvores brasileiras: manual de identificação e cultivo de plantas arbóreas nativas do Brasil. Plantarum. Nova Odessa, São Paulo, p.I52.
Radambrasil. 1975. Levantamento de Recursos Naturais. v, 8. MME/Departamento Nacional de Produçào Mineral. 428p.

Ramirez, N.; Arroyo, M. K. 1982. Mecanismos de dispersión y dinámica de regeneración en Copaifera pubiflora Benth (Caesalpinioideae) en los altos llanos centrales de Venezuela. Bol. Soc. Ven. de Cienc. Nat., 140:291-311.

Silva, S. J. R. da. 1998. Recursos tróficos de abelhas Apis mellifera L. (Hymenoptera, Apidae) em uma área de savana do estado de Roraima: fontes de néctar e pólen. Dissertação de Mestrado, Instituto Nacional de Pesquisas da Amazônia/ Universidade do Amazonas. Manaus, Amazonas. 88p.

SUDAM, 1984. Projeto de Hidrologia e Climatologia da Amazônia: Atlas climatológico da amazónia brasileira. Belém, Pará. (Publicação, 39). 44p. 